\title{
Association analysis of APO gene polymorphisms with ischemic stroke risk: a case-control study in a Chinese Han population
}

\author{
Rongjun Xiao ${ }^{1, *}$, Shuaiqi Sun ${ }^{1, *}$, Jiayi Zhang², Yongri Ouyang', Ning Zhang', Min \\ Yang ${ }^{2}$, Tianbo $\mathrm{Jin}^{2}$ and Ying $\mathrm{Xia}^{1}$ \\ ${ }^{1}$ Department of Neurosurgery, Affiliated Haikou Hospital of Xiangya Medical College of Central South University, Haikou \\ People's Hospital, Haikou, Hainan, China \\ 2 School of Life Sciences, Northwest University, Xi'an, Shaanxi, China \\ * These authors have Contributed equally to this work \\ Correspondence to: Tianbo Jin, email: jintianbo@gmail.com \\ Ying Xia, email: drxiaying@163.com
}

Keywords: APO; ischemic stroke; gene polymorphisms; case-control study; Chinese Han population

Received: January 10, 2017

Accepted: February 13, 2017

Published: February 20, 2017

Copyright: Xiao et al. This is an open-access article distributed under the terms of the Creative Commons Attribution License 3.0 (CC BY 3.0), which permits unrestricted use, distribution, and reproduction in any medium, provided the original author and source are credited.

\section{ABSTRACT}

This study aimed to assess the association of APO gene polymorphisms and ischemic stroke risk in a Chinese Han population. In this case-control study, we genotyped 14 single nucleotide polymorphisms (SNPs) in 3 APO genes in 488 cases and 503 controls using Sequenom Mass-ARRAY technology and evaluated their association with ischemic stroke using the $\mathrm{X} \mathbf{2}$ and genetic model analysis. In the allelic model analysis, we determined three SNPs were significantly associated with ischemic stroke: rs693 with a $p$ value of $0.042(O R=1.406 ; 95 \% C I=1.011-1.956)$, rs651821 with a $p$ value of $0.007(\mathrm{OR}=0.760 ; 95 \% \mathrm{CI}=0.622-0.929)$ and rs662799 with a $p$ value of $0.006(\mathrm{OR}=0.755 ; 95 \% \mathrm{CI}=0.618-0.923)$. In the genetic model analysis, we found the minor allele " $A$ " of rs693 was associated with an increased ischemic stroke risk in the additive model and dominant model. The minor allele "C" of rs651821 was associated with a decreased ischemic stroke risk in the additive model. The minor allele "G" of rs662799 was associated with a decreased ischemic stroke risk in the additive model. Additionally, strong linkage was found in 3 blocks constituted by rs1042034, rs676210, rs693, rs673548 in APOB; rs3791981, rs679899 in APOB; and rs651821, rs662799, rs17120035 in APOA5. Our data suggested that gene polymorphisms in the APO genes may exert influences ischemic stroke susceptibility in a Chinese Han population.

\section{INTRODUCTION}

In recent years, ischemic stroke is becoming the most seriously disabling illness in industrialized countries [1]. As the population growth and aging in the world, the incidence of ischemic stroke is increasing every year. We have to take action now to look for some novel targets for new therapeutic strategies [2]. Previous study have suggested that the ischemic stroke is a multifactorial disease which is influenced by many factors, such as age, gender, obesity, smoking status, history of hypertension, diabetes and abnormal lipid metabolism as well as gene variation $[3,4]$. Recent studies have identified several predisposing genes that are associated with ischemic stroke risk, including HDAC9 [5], LTC4S, ALOX5 [6], $A P O A 1, A P O B$ [7].

The protein encoded by $A P O A 1$ is the major protein component of high density lipoprotein (HDL) in plasma. Defects in APOAl are associated with HDL deficiencies, including Tangier disease and systemic nonneuropathic amyloidosis [8]. APOA1 is closely linked with $A P O A 5$, which is another apolipoprotein gene on 
chromosome 11. The apolipoprotein encoded by $A P O A 5$ regulates the plasma triglyceride levels. Previous study have found that APOA5 mutations are associated with hypertriglyceridemia and hyperlipoproteinemia type 5 [9].

The protein encoded by $A P O B$ is the main apolipoprotein of chylomicrons and low density lipoproteins (LDL). Mutations in $A P O B$ or its regulatory region cause hypobetalipoproteinemia, normotriglyceridemic hypobetalipoproteinemia and hypercholesterolemia [10]. Additionally, APO levels have a closely correlation with lipid levels in the human body, and APOB/APOA1 could be used for predicting of abnormal lipid metabolism related disease [7].

To date, several independent studies suggest that APOA1, APOA5 and APOB levels are risk factors for ischemic stroke risk in Western populations. However, little is known about the contribution of $A P O A 1, A P O A 5$ and $A P O B$ genes polymorphisms to ischemic stroke risk, especially in the Chinese Han population. We therefore performed a case-control study to investigate the associations between single nucleotide polymorphisms (SNPs) in $A P O A 1, A P O A 5$ and $A P O B$, and the risk of ischemic stroke in Chinese Han population.

\section{RESULTS}

This study included 488 ischemic stroke cases ( 325 men, 163 women; mean age $63.96 \pm 11.06$ years) and 503 healthy controls (196 men, 308 women; mean age 50.36 \pm 7.89 years $)$. The clinical characteristics of cases and controls are shown in Table 1. Age $(p<0.001)$ and sex $(p$ $<0.001)$ were significantly different between cases and healthy controls. Multivariate analyses were adjusted for age and sex.

To design the multiplexed SNPs MassEXTEND assay, we used Sequenom MassARRAY Assay Design 3.0 Software (PCR primers are shown in Table 2). The minor allele frequencies (MAFs) of the analyzed SNPs in the case and control groups are shown in Table 3. All SNPs were in Hardy-Weinberg equilibrium (HWE) in the controls $(p>0.05)$. We found three SNPs were significantly associated with ischemic stroke: rs693 with a $p$ value of $0.042(\mathrm{OR}=1.406 ; 95 \% \mathrm{CI}=1.011-1.956)$, rs651821 with a $p$ value of $0.007(\mathrm{OR}=0.760 ; 95 \% \mathrm{CI}=$ $0.622-0.929)$ and rs662799 with a $p$ value of $0.006(\mathrm{OR}=$ $0.755 ; 95 \% \mathrm{CI}=0.618-0.923$ ).

We further assessed the association between each SNP and ischemic stroke risk in an unconditional logistic

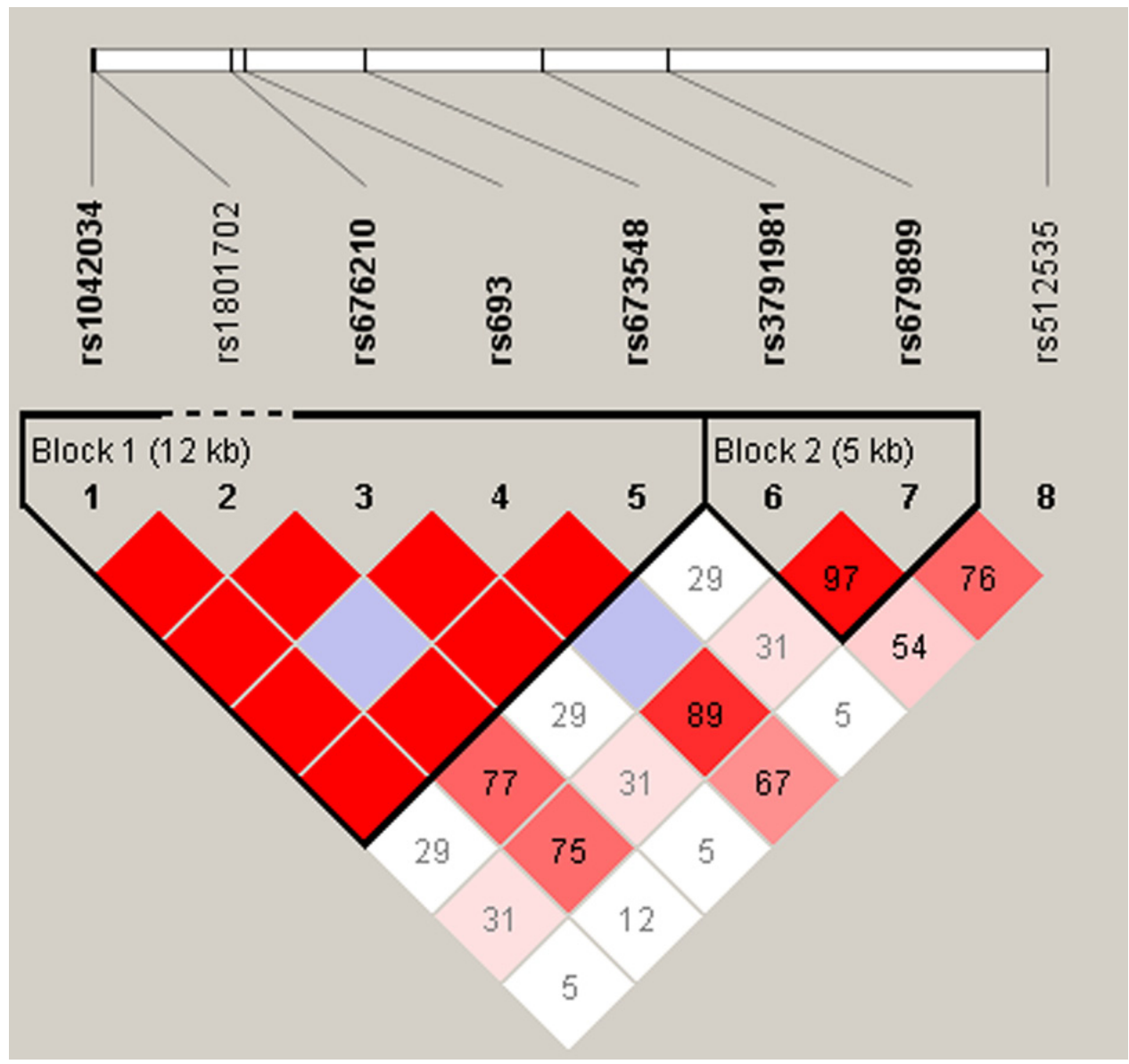

Figure 1: D' linkage map for the $8 \mathrm{SNPs}$ in $A P O B$. 
Table 1: Basic characteristics of case and control subjects.

\begin{tabular}{|c|c|c|c|c|c|}
\hline \multirow{2}{*}{ Variables } & \multicolumn{2}{|c|}{ Case $(n=488)$} & \multicolumn{2}{|c|}{ Control $(n=503)$} & \multirow{2}{*}{$p$ value } \\
\hline & No. & $\%$ & No. & $\%$ & \\
\hline \multicolumn{6}{|l|}{ Sex } \\
\hline Male & 325 & 66.6 & 195 & 38.9 & $p<0.001^{\mathrm{a}}$ \\
\hline Female & 163 & 33.4 & 308 & 61.1 & \\
\hline \multicolumn{6}{|l|}{ Age } \\
\hline Mean \pm SD & \multicolumn{2}{|c|}{$63.96 \pm 11.06$} & \multicolumn{2}{|c|}{$50.36 \pm 7.89$} & $p<0.001^{\mathrm{b}}$ \\
\hline
\end{tabular}

${ }^{a} P$ values were calculated by two-sided chi-square tests;

${ }^{b} P$ values were calculated from Student $t$ tests.

Table 2: PCR primers used for this study.

\begin{tabular}{|c|c|c|c|}
\hline SNP_ID & 1st-PCR primer sequences & 2nd-PCR primer sequences & UEP sequences \\
\hline rs1042034 & ACGTTGGATGATGAAGATTAAGGCATAGG & ACGTTGGATGATCCAAGATGAGATCAACAC & ATGAGATCAACACAATCTTCA \\
\hline rs 1801702 & ACGTTGGATGTCCTTTCGAGTTAAGGAAAC & ACGTTGGATGGGCTTTAAATACCTCTTGGG & TGATAAATCTTTCAACAGTTCC \\
\hline rs676210 & ACGTTGGATGATAGCTTGCCAAAAGTAGG & ACGTTGGATGTTTTCAAGTTCCTGACCTTC & ggtccAGTTCCTGACCTTCACATAC \\
\hline rs693 & ACGTTGGATGGGTATCGTTGAAGTTCCTGC & ACGTTGGATGCACATGAAGGCCAAATTCCG & aGCCAAATTCCGAGAGAC \\
\hline rs673548 & ACGTTGGATGCTTTCAGTGCATTGTCCAG & ACGTTGGATGAAGAGCAATGAACATTAGGC & GAACATTAGGCAAAAATACC \\
\hline rs 3791981 & ACGTTGGATGCTACCTAGCTACCTCAAATC & ACGTTGGATGGTTTTGAGAATGAAGAAACA & AGAATGAAGAAACAATAGCTC \\
\hline rs679899 & ACGTTGGATGTCCATGACAGTTGGAAGTTG & ACGTTGGATGATAACATGGTGTGTCAGCTC & CTGAAAAAGTTAGTGAAAGAAG \\
\hline rs512535 & ACGTTGGATGTTCCGGTGGGAAATGGGCAG & ACGTTGGATGCCTCATAGACATCTGGAACC & aCATGCATCGTTTCCTTC \\
\hline rs 651821 & ACGTTGGATGCTCCCTCCACCTGTCTTCT & ACGTTGGATGAGACCCACCTGAAAGAAGAG & CAGCCATGCTTGCCATTA \\
\hline rs662799 & ACGTTGGATGAGCATTTGGGCTTGCTCTCC & ACGTTGGATGTCTGAGCCCCAGGAACTGGA & cctGAACTGGAGCGAAAGT \\
\hline rs17120035 & ACGTTGGATGTACACACGTTCACAAGCTCC & ACGTTGGATGCTGGTGCAATGATGGTAGTG & GGATTGATTCAAGATGCATTTA \\
\hline rs9804646 & ACGTTGGATGCTGGGTTCTGATTCTGGTTG & ACGTTGGATGGTTTGAGGAGATCAAGTGGC & ACGTTGGATGCTTTCAGTGCATTGTCCAG \\
\hline rs 5072 & ACGTTGGATGTGTGACCCTGCCTGGAGAT & ACGTTGGATGCCGAGTCCTCACCTAATATC & gaatATGGTCTGGATGGAGAAAC \\
\hline rs632153 & ACGTTGGATGAGCTGTGCTCCTGGAGGCTG & ACGTTGGATGAGGGACATGAGCAACCCTTC & AGCTGGAGAAGGCAAAG \\
\hline
\end{tabular}

regression analysis, which was performed using three models: additive, dominant and recessive model (Table 4). The minor allele "A" of rs693 in $A P O B$ was associated with an increased ischemic stroke risk in the additive model $(\mathrm{OR}=1.583 ; 95 \% \mathrm{CI}=1.045-2.397 ; p=0.030)$ and dominant model $(\mathrm{OR}=1.610 ; 95 \% \mathrm{CI}=1.024$ $2.530 ; p=0.039$ ) respectively. The minor allele " $\mathrm{C}$ " of rs651821 in APOA5 was associated with a decreased ischemic stroke risk in the additive model $(\mathrm{OR}=0.773$; $95 \% \mathrm{CI}=0.597-0.999 ; p=0.040$ ). The minor allele " $\mathrm{G}$ " of rs662799 in APOA5 was associated with a decreased ischemic stroke risk in the additive model $(\mathrm{OR}=0.768$; $95 \% \mathrm{CI}=0.593-0.993 ; p=0.044)$.

We further characterized the SNPs in APOs using linkage disequilibrium (LD) and haplotype analyses.
Figure 1 showed the two blocks in $A P O B$ constructed by rs1042034, rs676210, rs693, rs673548 and rs3791981, rs679899 in chromosome 2 with D' $=1$. Figure 2 showed the block in APOA5 constructed by rs651821, rs662799 and rs17120035 in chromosome 11 with $D^{\prime}=1$. The association analysis between the three blocks and ischemic stroke risk was shown in Table 5. The haplotype "TGAG" in $A P O B$ constructed by rs1042034, rs676210, rs693 and rs673548 in chromosome 2 was associated with an increased ischemic stroke risk $(\mathrm{OR}=1.583 ; 95 \% \mathrm{CI}=$ 1.045 - 2.397; $p=0.031$ ). The haplotype "CGC" in APOA5 constructed by rs651821, rs662799 and rs17120035 in chromosome 11 was associated with a decreased ischemic stroke risk $(\mathrm{OR}=0.770 ; 95 \% \mathrm{CI}=0.595-0.997 ; p=$ 0.047). 
Table 3: Allele frequencies in cases and controls and odds ratio estimates for ischemic stroke risk (adjusted for gender and age).

\begin{tabular}{|c|c|c|c|c|c|c|c|c|c|c|}
\hline \multirow{2}{*}{ SNP ID } & \multirow{2}{*}{ Chromosome } & \multirow{2}{*}{ Position } & \multirow{2}{*}{\begin{tabular}{|l} 
Allele \\
A/B
\end{tabular}} & \multirow{2}{*}{ Gene } & \multirow{2}{*}{ Role } & \multirow{2}{*}{ HWE $p$} & \multicolumn{2}{|l|}{ MAF } & \multirow{2}{*}{ OR(95\%CI) } & \multirow{2}{*}{$p$ value } \\
\hline & & & & & & & Case & Control & & \\
\hline rs1042034 & 2 & 21225281 & $\mathrm{~T} / \mathrm{C}$ & $A P O B$ & Coding exon & 0.1247 & 0.297 & 0.282 & $1.075(0.885-1.305)$ & 0.467 \\
\hline rs1801702 & 2 & 21225485 & $\mathrm{G} / \mathrm{C}$ & $A P O B$ & Coding exon & 1 & 0.027 & 0.029 & $0.922(0.539-1.577)$ & 0.767 \\
\hline rs676210 & 2 & 21231524 & G/A & $A P O B$ & Coding exon & 0.1534 & 0.295 & 0.283 & $1.057(0.870-1.284)$ & 0.577 \\
\hline rs 693 & 2 & 21232195 & $\mathrm{~A} / \mathrm{G}$ & $A P O B$ & Coding exon & 0.2639 & 0.091 & 0.067 & 1.406(1.011-1.956) & $0.042 *$ \\
\hline rs673548 & 2 & 21237544 & G/A & $A P O B$ & Intron (boundary) & 0.1526 & 0.295 & 0.284 & $1.056(0.869-1.283)$ & 0.581 \\
\hline rs3791981 & 2 & 21245367 & G/A & $A P O B$ & Intron & 0.1267 & 0.046 & 0.051 & $0.905(0.600-1.365)$ & 0.634 \\
\hline rs679899 & 2 & 21250914 & G/A & $A P O B$ & Coding exon & 0.8762 & 0.184 & 0.173 & $1.081(0.859-1.361)$ & 0.505 \\
\hline rs512535 & 2 & 21267782 & $\mathrm{~T} / \mathrm{C}$ & $A P O B$ & Promoter & 0.7202 & 0.256 & 0.249 & $1.041(0.850-1.275)$ & 0.696 \\
\hline rs651821 & 11 & 116662579 & $\mathrm{C} / \mathrm{T}$ & APOA5 & 5' UTR & 0.9139 & 0.238 & 0.291 & $0.760(0.622-0.929)$ & $0.007 *$ \\
\hline rs662799 & 11 & 116663707 & G/A & APOA5 & Promoter & 1 & 0.238 & 0.292 & $0.755(0.618-0.923)$ & $0.006^{*}$ \\
\hline rs 17120035 & 11 & 116663851 & $\mathrm{~T} / \mathrm{C}$ & APOA5 & Promoter & 1 & 0.100 & 0.100 & $1.000(0.746-1.341)$ & 0.999 \\
\hline rs9804646 & 11 & 116665079 & $\mathrm{~T} / \mathrm{C}$ & APOA5 & Promoter & 0.8933 & 0.221 & 0.211 & $1.064(0.859-1.318)$ & 0.567 \\
\hline rs 5072 & 11 & 116707583 & $\mathrm{~A} / \mathrm{G}$ & $A P O A 1$ & Intron & 0.5463 & 0.333 & 0.333 & $1.001(0.831-1.207)$ & 0.988 \\
\hline rs632153 & 11 & 116710239 & $\mathrm{~T} / \mathrm{G}$ & $A P O A 1$ & Promoter & 0.4523 & 0.065 & 0.065 & $1.001(0.700-1.433)$ & 0.995 \\
\hline
\end{tabular}

SNP single nucleotide polymorphism, HWE Hardy-Weinberg equilibrium, MAF minor allele frequency, OR odds ratio, CI confidence interval.

${ }^{*} p \leq 0.05$ indicates statistical significance.

\section{DISCUSSION}

In the current study, we evaluated the association between fourteen SNPs in three $A P O$ genes and ischemic stroke risk in the Chinese Han population. We found the minor allele "A" of rs693 was associated with an increased ischemic stroke risk. The minor allele " $\mathrm{C}$ " of rs651821 and "G" of rs662799 have a protective role for ischemic stroke.

The SNP rs693 at chromosome 2p24.1 was located in the exon region of $A P O B$ gene. The minor allele " $\mathrm{A}$ " of rs693 in codon 3611 resulted in amino acid substitution of glutamine to arginine, which could further changed the LDL-receptor binding affinity [11]. Previous studies demonstrated rs693 have a closely correlation with cholesterol and LDL-cholesterol levels [12-15]. Our study demonstrated rs693 was associated with ischemic stroke risk in a Chinese Han population, the detailed mechanism of how the SNP affected the progressing of ischemic stroke deserved further investigation.

The SNP rs651821 and rs662799 at chromosome $11 \mathrm{q} 23.3$ was located in the $5^{\prime}$ UTR and promoter region of $A P O A 5$ gene respectively. As demonstrated by previous studies, the elevated triglyceride level may be an independent risk factor for ischemic stroke [16]. Human and animal data consistently show that the newly identified $A P O A 5$ gene may play an important role in the development of ischemic stroke and triglyceride metabolism [17, 18]. APOA5-1131T/C (rs662799), as one polymorphism site of $A P O A 5$, has been widely studied in ischemic stroke susceptibility. However, inconclusive results have been obtained. Some studies supported the conclusion that risk for ischemic stroke was associated with the polymorphism, whereas other studies drew converse conclusions [17-22]. Our study supported rs662799 was associated with ischemic stroke risk in a Chinese Han population, further meta-analysis will be need to confirm the results.

The haplotype analysis suggested that the combination of certain SNPs could increase or decrease the risk of ischemic stroke since the change of a certain SNP may affect the change of another SNP thus generating a joint effect in the progressing of ischemic stroke. The detailed mechanism of this phenomenon deserved further investigation. 
Table 4: Association between APO SNPs and ischemic stroke risk in multiple inheritance models (adjusted for gender and age)

\begin{tabular}{|c|c|c|c|c|c|c|c|}
\hline \multirow{2}{*}{ SNP ID } & \multirow{2}{*}{ Minor Allele } & \multicolumn{2}{|c|}{ Additive model } & \multicolumn{2}{|c|}{ Dominant model } & \multicolumn{2}{|c|}{ Recessive model } \\
\hline & & OR $(95 \% \mathrm{CI})$ & $p$ value & OR $(95 \% \mathrm{CI})$ & $p$ value & OR $(95 \% \mathrm{CI})$ & $p$ value \\
\hline rs1042034 & $\mathrm{T}$ & $1.143(0.895-1.461)$ & 0.284 & $1.218(0.881-1.684)$ & 0.233 & $1.111(0.642-1.923)$ & 0.707 \\
\hline rs1801702 & G & $0.962(0.483-1.917)$ & 0.912 & $0.940(0.463-1.909)$ & 0.864 & - & 0.999 \\
\hline rs676210 & G & $1.119(0.875-1.431)$ & 0.372 & $1.196(0.865-1.653)$ & 0.280 & $1.046(0.600-1.823)$ & 0.874 \\
\hline rs693 & A & $1.583(1.045-2.397)$ & $0.030 *$ & $1.610(1.024-2.530)$ & $0.039 *$ & $2.685(0.484-14.890)$ & 0.258 \\
\hline rs673548 & G & $1.109(0.867-1.419)$ & 0.409 & $1.180(0.853-1.632)$ & 0.319 & $1.044(0.599-1.818)$ & 0.880 \\
\hline rs3791981 & G & $0.770(0.457-1.297)$ & 0.326 & $0.792(0.450-1.393)$ & 0.419 & $0.276(0.022-3.536)$ & 0.323 \\
\hline rs679899 & $\mathrm{G}$ & $1.019(0.757-1.372)$ & 0.901 & $1.059(0.751-1.492)$ & 0.745 & $0.795(0.316-2.003)$ & 0.627 \\
\hline rs512535 & $\mathrm{T}$ & $0.971(0.748-1.262)$ & 0.828 & $0.965(0.751-1.492)$ & 0.829 & $0.965(0.502-1.857)$ & 0.915 \\
\hline rs 651821 & $\mathrm{C}$ & $0.773(0.597-0.999)$ & $0.040^{*}$ & $0.743(0.536-1.028)$ & 0.073 & $0.659(0.352-1.231)$ & 0.190 \\
\hline rs662799 & G & $0.768(0.593-0.993)$ & $0.044 *$ & $0.735(0.531-1.017)$ & 0.063 & $0.660(0.353-1.233)$ & 0.193 \\
\hline rs17120035 & $\mathrm{T}$ & $0.999(0.688-1.453)$ & 0.998 & $0.971(0.644-1.462)$ & 0.887 & $1.472(0.323-6.588)$ & 0.613 \\
\hline rs9804646 & $\mathrm{T}$ & $1.071(0.812-1.413)$ & 0.626 & $1.056(0.758-1.472)$ & 0.746 & $1.261(0.589-2.700)$ & 0.551 \\
\hline rs 5072 & A & $0.915(0.716-1.170)$ & 0.480 & $0.869(0.627-1.204)$ & 0.398 & $0.961(0.567-1.627)$ & 0.882 \\
\hline rs632153 & $\mathrm{T}$ & $1.028(0.641-1.651)$ & 0.908 & $1.050(0.644-1.711)$ & 0.844 & $0.355(0.008-16.740)$ & 0.599 \\
\hline
\end{tabular}

SNP single nucleotide polymorphism, OR odds ratio, CI confidence interval.

$* p \leq 0.05$ indicates statistical significance.

Table 5: Haplotype frequencies of APO genes and the association with ischemic stroke risk in cases and control (adjusted for gender and age).

\begin{tabular}{|c|c|c|c|c|c|c|c|c|c|}
\hline \multirow{2}{*}{ Chromosome } & \multirow{2}{*}{ Gene } & \multirow{2}{*}{ SNPs } & \multirow{2}{*}{ Haplotype } & \multirow{2}{*}{\begin{tabular}{|l} 
Frequency \\
Case \\
\end{tabular}} & \multirow{2}{*}{\begin{tabular}{|l} 
Frequency \\
Control \\
\end{tabular}} & \multirow{2}{*}{ OR } & \multicolumn{2}{|c|}{$95 \%$ CI } & \multirow{2}{*}{$p$ value } \\
\hline & & & & & & & & & \\
\hline \multirow{3}{*}{ chr2 } & \multirow{3}{*}{$A P O B$} & \multirow{3}{*}{ rs1042034|rs676210|rs693|rs673548 } & TGAG & 0.091 & 0.067 & 1.583 & 1.045 & 2.397 & $0.030^{*}$ \\
\hline & & & TGGG & 0.203 & 0.216 & 0.940 & 0.714 & 1.238 & 0.659 \\
\hline & & & CAGA & 0.701 & 0.717 & 0.873 & 0.683 & 1.115 & 0.276 \\
\hline \multirow{3}{*}{ chr2 } & \multirow{3}{*}{$A P O B$} & \multirow{3}{*}{ rs3791981|rs679899 } & GG & 0.046 & 0.050 & 0.774 & 0.459 & 1.306 & 0.338 \\
\hline & & & $\mathrm{AG}$ & 0.138 & 0.123 & 1.139 & 0.815 & 1.592 & 0.447 \\
\hline & & & AA & 0.816 & 0.826 & 0.984 & 0.731 & 1.324 & 0.913 \\
\hline \multirow{3}{*}{ chr11 } & \multirow{3}{*}{ APOA5 } & \multirow{3}{*}{ rs651821|rs662799|rs17120035 } & TAT & 0.100 & 0.100 & 1.000 & 0.688 & 1.453 & 0.998 \\
\hline & & & CGC & 0.238 & 0.291 & 0.770 & 0.595 & 0.997 & $0.047^{*}$ \\
\hline & & & TAC & 0.662 & 0.607 & 1.245 & 0.985 & 1.573 & 0.067 \\
\hline
\end{tabular}

SNP single nucleotide polymorphism, OR odds ratio, CI confidence interval.

${ }^{*} p \leq 0.05$ indicates statistical significance.

Our study had several intrinsic limitations. For example, ischemic stroke is a very complicated process, and environment factors such as eating and exercise habits are important risk factors for ischemic stroke. Because our study had a relatively small sample size, and it did not incorporate data regarding eating and exercise habits, we could not explore the interactions between genetic polymorphisms and environmental factors in ischemic stroke. Therefore, the relationship between $A P O s$ polymorphisms and environment factors in ischemic stroke must be evaluated in future studies.

In sum, our present study provided evidence that three SNPs rs693, rs651821 and rs662799 were associated with ischemic stroke risk in a Chinese Han population, which could be used in clinical diagnosis of ischemic stroke. Further investigations are deserved to discover 
more susceptible loci to other cardiovascular diseases, and to clarify the molecular mechanism of ischemic stroke.

\section{MATERIALS AND METHODS}

\section{Study subjects}

All the participants in this study were Han Chinese lived in Hainan Province. A total of 488 patients who diagnosed with ischemic stroke were recruited from the Haikou People's Hospital between January 2013 and February 2016. They were all newly diagnosed to be ischemic stroke patients according to the International
Classification of Disease (9th revision, codes 430 to 438 ) on the basis of history, clinical symptoms, physical examination, and cranial computed tomography or magnetic resonance imaging. Patients with hemorrhagic stroke, subarachnoid hemorrhage, transient ischemic attack, traumatic brain injuries, infectious diseases, and tumors were excluded in this study.

We also recruited 503 controls at the Haikou People's hospital. Controls were healthy, unrelated individuals selected randomly from the medical examination center of the hospital. All participants were informed of the procedures and purpose of the study, and each participant provided signed informed consent forms. The use of human samples in this study was approved by the Ethics Committees of the local participating hospitals

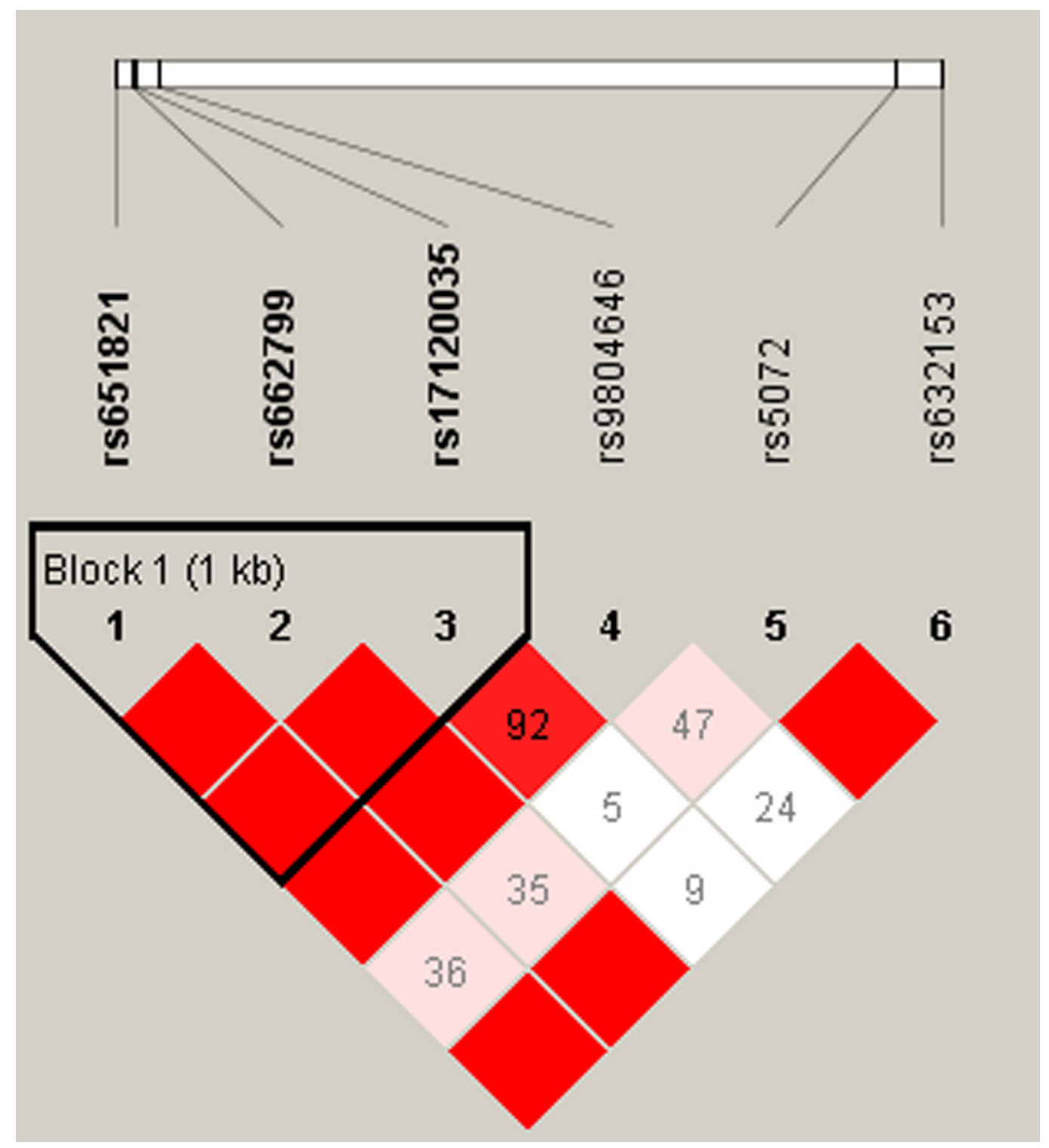

Figure 2: D' linkage map for the $6 \mathrm{SNPs}$ in $A P O A 1$ and $A P O A 5$. A standard color scheme was used to display linkage disequilibrium $(\mathrm{LD})$, with bright red corresponding to strong $\mathrm{LD}\left(\mathrm{LOD}=2, D^{\prime}=1\right.$ ), white corresponding to no $\mathrm{LD}$ (LOD $\left.<2, D^{\prime}<1\right)$, and pink/red (LOD $\left.=2, D^{\prime}<1\right)$ and blue $\left(\mathrm{LOD}<2, D^{\prime}=1\right)$ corresponding to intermediate $\mathrm{LD}$. 
and was in accordance with Department of Health and Human Services (DHHS) regulations for protection of human research subjects.

\section{Polymorphisms selection and genotyping assays}

Candidate SNPs in the $A P O$ genes were selected from previously published polymorphisms associated with stroke $[23,24]$. Validated tSNPs were selected with a MAF $>5 \%$ in the HapMap CHB population. A total of 14 SNPs in the $A P O$ genes including 2 SNPs in $A P O A 1$, 4 SNPs in $A P O A 5$ and 8 SNPs in $A P O B$ were selected for further genotyping. Genomic DNA was extracted from peripheral blood leukocytes using the GoldMag ${ }^{\mathbb{R}}$ nanoparticles method (GoldMag Ltd. Xi'an, China) according to the manufacturer's instructions and DNA concentration was measured using the NanoDrop 2000 (Thermo Scientific, Waltham, Massachusetts, USA). We used Sequenom MassARRAY Assay Design 3.0 Software to design Multiplexed SNP MassEXTEND assays [25]. SNP genotyping was performed using the Sequenom MassARRAY RS1000 with a standard protocol recommended by the manufacturer [25]. Data management and analyses were performed using the Sequenom Typer 4.0 software as previously described $[25,26]$.

\section{Statistical analysis}

Statistical analyses were performed using Microsoft Excel (Redmond, WA, USA) and SPSS 16.0 statistical package (SPSS, Chicago, IL, USA). All $p$ values in this study were two-sided, and $p \leq 0.05$ was considered as the statistical significance threshold [27]. An exact test was used to assess the departure of each SNP frequency from Hardy-Weinberg equilibrium (HWE) in controls. We compared allele frequencies between cases and controls using a $\chi^{2}$ test. $p$ values were calculated using unconditional logistic regression analysis with adjustment for age and gender [28, 29].

The three genetic models (dominant, recessive and additive) were applied by PLINK software (http://www. cog-genomics.org/plink2/) to assess the association of single SNPs with the risk of ischemic stroke. The odds are a way of representing probability, especially familiar for betting. The confidence intervals are standard errors for the $\log$ odds ratio. The odds ratios (ORs) and $95 \%$ confidence intervals $(95 \%$ CIs) were calculated by unconditional logistic regression analyses adjusted for age and sex [30].

We used the Haploview software package (version 4.2) to analyze the linkage disequilibrium (LD), haplotype construction, genetic association at polymorphism loci and a D' value greater than 0.8 indicated that the related SNPs formed one block [31]. Marker information, including name and location is loaded separately. The program filters out markers which fall below $5 \%$ for subsequent steps. Haplotypes with frequencies $>1 \%$ were selected for analysis of ischemic stroke risk.

\section{ACKNOWLEDGMENTS}

This work is supported by National Natural Science Foundations (NO.81360190). We are grateful to all the patients and individuals in the study who made this work possible. We would also like to thank the clinicians and hospital staffs who contributed to data collection for this study.

\section{CONFLICTS OF INTEREST}

There is no conflict of interest.

\section{REFERENCES}

1. Mukherjee D, Patil CG. Epidemiology and the global burden of stroke. World Neurosurg. 2011 (Suppl); 76:S8590.

2. Feigin VL. Stroke in developing countries: can the epidemic be stopped and outcomes improved? Lancet Neurol. 2007; 6:94-97.

3. O'Donnell MJ, Xavier D, Liu L, Zhang H, Chin SL, RaoMelacini P, Rangarajan S, Islam S, Pais P, McQueen MJ, Mondo C, Damasceno A, Lopez-Jaramillo P, et al, and INTERSTROKE investigators. Risk factors for ischaemic and intracerebral haemorrhagic stroke in 22 countries (the INTERSTROKE study): a case-control study. Lancet. 2010; 376:112-23.

4. Sacco RL, Ellenberg JH, Mohr JP, Tatemichi TK, Hier DB, Price TR, Wolf PA. Infarcts of undetermined cause: the NINCDS Stroke Data Bank. Ann Neurol. 1989; 25:382-90.

5. Bellenguez C, Bevan S, Gschwendtner A, Spencer CC, Burgess AI, Pirinen M, Jackson CA, Traylor M, Strange A, Su Z, Band G, Syme PD, Malik R, et al, and International Stroke Genetics Consortium (ISGC), and Wellcome Trust Case Control Consortium 2 (WTCCC2). Genome-wide association study identifies a variant in HDAC9 associated with large vessel ischemic stroke. Nat Genet. 2012; 44:32833.

6. Wang GN, Zhang JS, Cao WJ, Sun H, Zhang J, Wang Y, Xiao H. Association of ALOX5, LTA4H and LTC4S gene polymorphisms with ischemic stroke risk in a cohort of Chinese in east China. World J Emerg Med. 2013; 4:32-37.

7. Dong H, Chen W, Wang X, Pi F, Wu Y, Pang S, Xie Y, Xia F, Zhang Q. Apolipoprotein A1, B levels, and their ratio and the risk of a first stroke: a meta-analysis and case-control study. Metab Brain Dis. 2015; 30:1319-30.

8. Tribut O, Lessard Y, Reymann JM, Allain H, Bentué-Ferrer D. Pharmacogenomics. Med Sci Monit. 2002; 8:RA152-63. 
9. Xie HG, Kim RB, Wood AJ, Stein CM. Molecular basis of ethnic differences in drug disposition and response. Annu Rev Pharmacol Toxicol. 2001; 41:815-50.

10. Kazui M, Nishiya Y, Ishizuka T, Hagihara K, Farid NA, Okazaki O, Ikeda T, Kurihara A. Identification of the human cytochrome P450 enzymes involved in the two oxidative steps in the bioactivation of clopidogrel to its pharmacologically active metabolite. Drug Metab Dispos. 2010; 38:92-99.

11. Al-Bustan SA, Alnaqeeb MA, Annice BG, Ebrahim GA, Refai TM. Genetic association of APOB polymorphisms with variation in serum lipid profile among the Kuwait population. Lipids Health Dis. 2014; 13:157.

12. Ruixing Y, Guangqin C, Yong W, Weixiong L, Dezhai Y, Shangling P. Effect of the 3'APOB-VNTR polymorphism on the lipid profiles in the Guangxi Hei Yi Zhuang and Han populations. BMC Med Genet. 2007; 8:45.

13. Kallel A, Jemaa R, Feki M, El Asmi M, Souissi M, Sanhaji H, Haj-Taieb S, Omar S, Kaabachi N. XbaI polymorphism of apolipoprotein B gene in a Tunisian population: alleles frequencies and relationship with plasma lipid parameters. [Article in French]. Ann Biol Clin (Paris). 2007; 65:265-70.

14. Tsunoda K, Harihara S, Tanabe Y, Dashnyam B. Polymorphism of the apolipoprotein $\mathrm{B}$ gene and association with plasma lipid and lipoprotein levels in the Mongolian Buryat. Biochem Genet. 2012; 50:249-68.

15. Bentzen J, Jørgensen $T$, Fenger $M$. The effect of six polymorphisms in the Apolipoprotein B gene on parameters of lipid metabolism in a Danish population. Clin Genet. 2002; 61:126-34.

16. Kim OY, Chung HK, Shin MJ. Higher levels of serum triglyceride and dietary carbohydrate intake are associated with smaller LDL particle size in healthy Korean women. Nutr Res Pract. 2012; 6:120-25.

17. Havasi V, Szolnoki Z, Talian G, Bene J, Komlosi K, Maasz A, Somogyvari F, Kondacs A, Szabo M, Fodor L, Bodor A and Melegh B. Apolipoprotein A5 gene promoter region $\mathrm{T}-1131 \mathrm{C}$ polymorphism associates with elevated circulating triglyceride levels and confers susceptibility for development of ischemic stroke. Journal of molecular neuroscience . 2006; 29:177-183.

18. Pennacchio LA, Rubin EM. Apolipoprotein A5, a newly identified gene that affects plasma triglyceride levels in humans and mice. Arterioscler Thromb Vasc Biol. 2003; 23:529-34.

19. Maasz A, Kisfali P, Jaromi L, Horvatovich K, Szolnoki Z, Csongei V, Safrany E, Sipeky C, Hadarits F and Melegh B. Apolipoprotein A5 gene IVS3 G476A allelic variant confers susceptibility for development of ischemic stroke. Circulation Journal. 2008; 72:1065-1070.

20. Maász A, Kisfali P, Szolnoki Z, Hadarits F, Melegh B. Apolipoprotein A5 gene C56G variant confers risk for the development of large-vessel associated ischemic stroke. J
Neurol. 2008; 255:649-54.

21. Martinelli N, Trabetti E, Bassi A, Girelli D, Friso S, Pizzolo F, Sandri M, Malerba G, Pignatti PF, Corrocher R, Olivieri O. The $-1131 \mathrm{~T}>\mathrm{C}$ and S19W APOA5 gene polymorphisms are associated with high levels of triglycerides and apolipoprotein C-III, but not with coronary artery disease: an angiographic study. Atherosclerosis. 2007; 191:409-17.

22. Vaessen SF, Schaap FG, Kuivenhoven JA, Groen AK, Hutten BA, Boekholdt SM, Hattori H, Sandhu MS, Bingham SA, Luben R, Palmen JA, Wareham NJ, Humphries SE, et al. Apolipoprotein A-V, triglycerides and risk of coronary artery disease: the prospective EpicNorfolk Population Study. J Lipid Res. 2006; 47:2064-70.

23. O’Donnell MJ, Xavier D, Liu L, Zhang H, Chin SL, RaoMelacini P, Rangarajan S, Islam S, Pais P, McQueen MJ, Mondo C, Damasceno A, Lopez-Jaramillo P, et al, and INTERSTROKE investigators. Risk factors for ischaemic and intracerebral haemorrhagic stroke in 22 countries (the INTERSTROKE study): a case-control study. Lancet. 2010; 376:112-23.

24. Della-Morte D, Guadagni F, Palmirotta R, Testa G, Caso V, Paciaroni M, Abete P, Rengo F, Ferroni P, Sacco RL, Rundek T. Genetics of ischemic stroke, strokerelated risk factors, stroke precursors and treatments. Pharmacogenomics. 2012; 13:595-613.

25. Gabriel S and Ziaugra L. SNP genotyping using Sequenom MassARRAY 7K platform. Current protocols in human genetics. 2004:2.12. 11-12.12. 16.

26. Thomas RK, Baker AC, Debiasi RM, Winckler W, Laframboise T, Lin WM, Wang M, Feng W, Zander T, MacConaill L, Lee JC, Nicoletti R, Hatton C, et al. Highthroughput oncogene mutation profiling in human cancer. Nat Genet. 2007; 39:347-51.

27. Song MK, Lin FC, Ward SE, Fine JP. Composite Variables: when and How. Nurs Res. 2012.

28. Adamec C. Example of the use of the nonparametric test. Test X2 for comparison of 2 independent examples. [Article in Czech]. Cesk Zdrav. 1964; 12:613-19.

29. Bland JM, Altman DG. Statistics notes. The odds ratio. BMJ. 2000; 320:1468.

30. Purcell S, Neale B, Todd-Brown K, Thomas L, Ferreira MA, Bender D, Maller J, Sklar P, de Bakker PI, Daly MJ, Sham PC. PLINK: a tool set for whole-genome association and population-based linkage analyses. Am J Hum Genet. 2007; 81:559-75.

31. Barrett JC, Fry B, Maller J, Daly MJ. Haploview: analysis and visualization of LD and haplotype maps. Bioinformatics. 2005; 21:263-65. 